\title{
A educação como formação ou "cultivo de si" em Friedrich Nietzsche

\section{Resumo}

Objetivamos aqui discutir a importância de uma educação como formação (Bildung) e cultivo de si em Nietzsche, filósofo conhecido pelo caráter intempestivo de seus escritos. Sua abordagem da educação é, na verdade, um profundo questionamento da própria função e propósito não só da prática educativa, mas do próprio sentido da cultura, a qual ele diagnosticou como estando, em sua época, não mais voltada para a formação total do indivíduo o oposto de uma educação como cultivo de si, isto é: voltada para o desenvolvimento das potencialidades individuais de cada um. Nosso ponto de partida é a obra III Consideração Intempestiva: Schopenhauer Educador, de 1874.

Palavras-chave: Nietzsche; Filosofia da Educação; Filosofia Alemã.

\begin{abstract}
We aim to discuss the importance of an education as formation (Bildung) and self-cultivation in Nietzsche, philosopher known for the untimely nature of his writings. His approach to education is actually a profound questioning of the very function and purpose not only of educational practice but the very meaning of culture, which he diagnosed, in his time, as no more focused on the full development of the individual but on the opposite of an education as self-cultivation, that is, focused on the development of the potential of each. Our starting point is the work Third Untimely Meditations, Schopenhauer as Educator.
\end{abstract}

Keywords: Nietzsche; Philosophy of Education; German Philosophy. 


\section{Introdução}

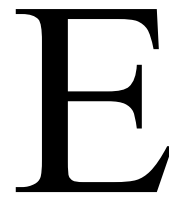

ste artigo pretende discutir a questão da educação como formação (Bildung) e cultivo de si em Nietzsche, filósofo conhecido pelo caráter intempestivo de seus escritos, extremamente críticos.

Pretendemos alcançar que sua abordagem da educação é, na verdade, não apenas um profundo questionamento da própria função e propósito da prática educativa, mas, antes, do próprio sentido da cultura, a qual ele diagnosticou como estando, em sua época, não mais voltada para a formação total do indivíduo - o oposto de uma educação como cultivo de si, isto é: voltada para o desenvolvimento das potencialidades individuais de cada um.

Para tanto, partiremos da apresentação do que Friedrich Nietzsche valoriza como "educação e cultura autênticas", as quais, como se irá investigar, detém estreita relação com a afirmação da vida, mesmo em suas contradições - questão que será progressivamente desenvolvida com vigor cada vez maior na obra Nietzschiana. É somente dentro deste escopo que as críticas de Nietzsche à educação e cultura de sua época (que entende como decadentes) podem ser desdobradas. Nosso pano de fundo será, sobretudo, a obra III Consideração Intempestiva: Schopenhauer Educador, escrita em 1874 e que apresenta a figura de Schopenhauer como mestre, em seu caráter modelar para sua própria formação. Usamos como base, em nossa discussão, o original em alemão publicado pela editora Carl Hanser Verlag, no volume I da Werke in zwei Band, em 1954. As citações, contudo, serão a partir da edição brasileira da obra, de 2004, a fim de facilitar o acesso. Não almejamos aqui, contudo, a exposição sistemática e pontual deste texto, antes almejamos discutir a problemática mencionada conforme esta se desdobra na obra citada e através de necessárias pontes com outros textos e 
elementos presentes à obra de Nietzsche vista em perspectiva, à medida em que estes possam se fazer necessários à plena discussão.

\title{
A possibilidade de cultura e educação autênticas
}

Quando falamos sobre a possibilidade de cultura e educação autênticas em Nietzsche, é em torno do conceito de Bildung - conceito fundamental da filosofia alemã desde o século XVIII - que nos movemos.

\begin{abstract}
A palavra alemã Bildung significa, genericamente, "cultura" e pode ser considerada o duplo germânico da palavra Kultur, de origem latina. [...] Utilizamos Bildung para falar no grau de "formação" de um indivíduo, um povo, uma língua, uma arte: e é a partir do horizonte da arte que se determina, no mais das vezes, Bildung. Sobretudo, a palavra alemã tem uma forte conotação pedagógica e designa a formação como processo. Por exemplo, os anos de juventude de Wilhelm Meister, no romance de Goethe, são seus Lehrjahre, seus anos de aprendizado, onde ele aprende somente uma coisa, sem dúvida decisiva: aprende a formar-se (sich bilden). (BIRMAN apud SUAREZ, 2005, p.193)
\end{abstract}

O ideal de uma educação e formação autêntica se fará presente em Goethe e nos românticos, se inspirando de forma magistral na Paideia grega - um sentido perdido de educação como formação ético-artística da bela individualidade e do cidadão ideal. Para Nietzsche, inclusive, a educação nunca é um projeto coletivo para as massas, pois é um projeto individual, autocentrado. 
A oposição entre o individual e o coletivo, entre o singular e o padronizado, é uma das polaridades mais características da modernidade. Da teoria política, passando pelas teorias morais e epistemológicas, até a inserção nas discussões estéticas, essa polaridade marcou também, e continua marcando, os discursos sobre a formação, hoje calcadas na generalização e universalização. (WEBER, 2009, p.253)

É muito difícil pensar a partir da contribuição nietzschiana para a educação sem adentrar esta polarização. Como pensar uma educação como cultivo de si? A verdadeira formação, para Nietzsche, é de inspiração "clássica", na medida em que o conceito de Bildung e o de Paideia dialogam, visando a formação de espíritos livres - um espírito tão livre talvez quanto virá a ser o Zaratustra, na futura obra de Nietzsche (MACHADO, 1999). É um tipo de formação que pode ser acusado de aristocrático - mas não no sentido usual e pérfido do termo - a 'cultura dos melhores' aqui não tem a ver com uma classe social, mas sim com a perspectiva de visar a formação dos melhores: uma cultura de seres humanos que plenamente desenvolvam suas potencialidades, algo que não pode ser alcançado nem através da erudição microscópica do especialista, nem pode ser atrelado à pura formação de "profissionais" para meramente disputarem uma vaga no mercado de trabalho. A formação do indivíduo, para Nietzsche, deve se pautar para além das necessidades econômicas e/ou de subsistência, antes devendo visar a formação integral do homem.

Um ponto que assim se faz interessante destacar é o de que Nietzsche não opõe vida e conhecimento, como usualmente ocorre no pensamento metafísico (com a vida e/ou a natureza sendo inferiorizada). Ao 
contrário. Nietzsche emparelha educação e natureza, ao invés de opô-las ou subjugar uma a outra. Se no texto Sobre o futuro de nossos estabelecimentos de ensino (2003), Nietzsche classifica os métodos atuais de educação como antinaturais, uma educação autêntica seria, ao contrário, a autoafirmação da natureza, como pode ser apreendido da III Intempestiva. A educação como Bildung se configura para Nietzsche, portanto, não em oposição à natureza, mas como aquilo através do qual a physis poderia alcançar sua máxima potência, através do grande homem, do homem verdadeiro, do gênio - pois o gênio, no entender de Nietzsche, é essa excrecência da natureza (pois não é o homem antes de tudo, parte da natureza?) sua verdadeira realização e ponto de culminância. Logo não deveria ser este o objetivo de toda cultura (Bildung)?

Os homens verdadeiros, aqueles que não são mais animais, os filósofos, os artistas e os santos; logo que eles aparecem - e com este aparecimento - a natureza que jamais dá saltos dá o seu único salto, e este é um salto de alegria, pois, pela primeira vez, ela percebe que chegou à sua finalidade $[. .$.$] .$

[...] Este é o pensamento fundamental da cultura, na medida em que esta só pode atribuir uma única tarefa a cada um de nós: incentivar o nascimento do filósofo, do artista e do santo em nós e fora de nós, e trabalhar assim para a realização [Vollendung] da natureza. (NIETZSCHE, 2003, p. 179-180)

Neste sentido, é que se pode afirmar que 
o papel da educação é então libertar estas forças interiores que a natureza colocou nos homens para a sua elevação e realização: as forças instintivas e plásticas que permitem a eles realizar suas obras, sobretudo as obras mais elevadas. (MELO, 2003, p. 34)

A educação, para Nietzsche, deveria encarar o educando, então, como mais que simples repositório da cultura de sua época, mas antes como alguém capaz de pensar por si mesmo, pensar a própria experiência e criar seus próprios valores e parâmetros. A educação deve ser o caminho para "tornar-se o que se é". Uma cultura autêntica não visa a formação de indivíduos em série, em um processo absolutamente impessoal como nas escolas modernas. Nietzsche defende uma educação individualizada (que conduza ao verdadeiro cultivo de si!), passada de mestre a discípulo, através de uma relação pessoal. Por isso, nesse ensaio, a exacerbação da necessidade de um mestre - visualizado então por Nietzsche, em seu caso pessoal, na figura de Schopenhauer.

\section{Schopenhauer como "modelo"}

Não podemos esquecer que a III Intempestiva tem como ponto marcante também a afirmação da necessidade de homens que sirvam de modelo na educação intelectual e moral dos indivíduos - educando-os através do exemplo, e não apenas através de palavras vazias. Enfim, o problema central aqui é da necessidade de "mestres" no sentido lato da palavra, e não de eruditos, de meros especialistas, palavras que falam de "filosofia", que falam sobre o conhecimento, mas não o "vivem".

Para Nietzsche, Schopenhauer foi um mestre, um exemplo de resistência em sua posição contrária ao hegelianismo, na época em que este 
dominava os meios acadêmicos alemães, posição essa que seria um dos motivos por trás de Schopenhauer não ter conseguido levar adiante a sonhada carreira acadêmica, tendo vivido como negociante. Schopenhauer conseguiu não perder a "honestidade de não mentir jamais, não mentir para ninguém, não mentir - sobretudo! - para si mesmo". Schopenhauer, como todo gênio, como todo indivíduo que se desvincula do rebanho, esteve sujeito a dois terríveis monstros: solidão e ostracismo. São esses os monstros, os perigos que muitas vezes destroem o indivíduo, impedindo o pleno desenvolvimento de sua genialidade.

Esta, como pode ser observado, não deixa de ser uma maneira (velada) de Nietzsche abordar ainda a temática de ser necessário criar instituições que acolham o gênio. Pensar a escola como o lugar que permita a genialidade deitar raízes e se desenvolver é uma perspectiva assas desafiadora. Mas, como destaca Nietzsche, seria muito difícil para o gênio viver em meio a turba e suas exigências cotidianas de rebanho.

Nossos Hölderlin e Kleist, e tantos outros, morreram por causa do seu caráter estranho, e não poderiam suportar o clima da pretensa cultura alemã. Somente as naturezas de ferro, como Beethoven, Goethe, Schopenhauer e Wagner, puderam torná-la boa. (NIETZSCHE, 2003, p. 152)

O que sobressai é a dificuldade, o perigo que os "homens excepcionais enfrentam por viverem numa sociedade demasiadamente ligada à norma ordinária" (NIETZSCHE, 2003, p. 152). O grande mérito que Nietzsche dá a Schopenhauer como educador, como modelo inspirador, é sua postura diante de sua época. Schopenhauer revela um caráter intempestivo: é isso que o torna grande. Ele conseguiu ir além das mazelas 
de sua época. Ser capaz de ir além da tábua de valores do próprio tempo, de criar sua própria régua, é isso que o constituiria como "homem superior":

Se de fato preferirmos considerar todo grande homem como o verdadeiro filho de seu tempo e como aquele que sofre, em todo caso, com todas as mazelas deste tempo, da maneira mais intensa e com mais sensibilidade do que todos os homens mais medíocres, o combate deste grande homem contra seu tempo só aparentemente é um combate absurdo e destruidor contra si mesmo. Mas isto é somente na aparência, pois, no seu tempo, ele combate o que o impede de ser grande, o que para ele só pode exatamente significar: ser livre e totalmente si mesmo. Segue-se que sua hostilidade é no fundo dirigida contra o que está nele próprio, certamente, mas não é verdadeiramente ele próprio, dirigida contra a mistura impura e confusa de elementos incompatíveis para sempre inconciliáveis, contra a falsa união do atual com seu próprio caráter intempestivo [...] (NIETZSCHE, 2003, p. 162).

Porém, acerca da relação de Nietzsche com Schopenhauer, algumas observações podem ser feitas. A terceira Intempestiva encontra-se em um ponto intermédio do pensamento nietzschiano. É interessante ver a junção que Nietzsche já faz entre cultura e vida, embora ainda estivesse apenas começando a assumir a plena afirmação da vida em sua inteireza, como virá ocorrer de forma fremente em sua obra posterior. Como observa Scarlet Marton (1993, p.11), 
a homenagem que Nietzsche presta aos mestres já tem [então] sabor de despedida. Mais tarde, em sua autobiografia, dirá que quando então falara de Schopenhauer e Wagner [nas Intempestivas], estivera de fato a falar de si mesmo.

Nietzsche, nesse texto, já apresenta indícios de vir a transformar o pessimismo negador da vontade humana de Schopenhauer diante da tragicidade da vida em uma vontade afirmativa da própria vida em sua inteireza, mesmo em seus aspectos mais sombrios. Se para Schopenhauer a solução ao caráter trágico da existência foi a negação da vontade, para Nietzsche era cada vez mais sua afirmação. O pessimismo de Schopenhauer afirma o ceticismo diante da ausência de sentido (metafísico) da existência, de uma vida guiada por uma vontade cega de viver, absurda, desprovida de propósito ou significado, que se revela no mundo somente como carência e dor. (MACHADO, 1999)

Ainda que inicialmente tenha compactuado com o pensamento de Schopenhauer, Nietzsche acabaria por não sucumbir ao desespero, à desistência e à negação da vontade individual por ele propostas, antes vindo a afirmar cada vez mais e de forma incondicional a vida - a vida em totalidade, a vida em sua inteireza trágica - com isso ultrapassando o conformismo que poderia nascer da constatação do absurdo da vida. Apesar das diferenças entre o pensamento de Nietzsche e de Schopenhauer não serem ainda tão latentes nos escritos sobre a educação, estas viriam a aumentar cada vez mais com o tempo. Contudo, a questão da estreita relação de uma cultura autêntica estar ligada à construção de si e à afirmação da vida, é uma temática já subjacente a toda abordagem que Nietzsche realiza acerca da figura de Schopenhauer como educador. 


\section{Nietzsche e a crítica à "formação" na cultura moderna}

A crítica de Nietzsche à educação e à cultura em sua época insere-se em um panorama maior de mudanças, que vinham se processando na Alemanha desde meados do século XVIII, não só no plano político (como a unificação dos vários Estados alemães) mas também no que se refere às crescentes modernização e industrialização da Alemanha (tardias em relação ao processo de industrialização da França e da Inglaterra), as quais, somadas à ascensão da burguesia, viriam a significar drásticas mudanças políticas, econômicas e culturais para esse povo. Até então, como destaca Marton (1993), a cultura e a educação se inseriam no contexto do Romantismo Alemão, que valorizava os autores, modelos e ideais clássicos, garantindo o caráter de criação desinteressada, desligada de intenções utilitárias. Esse caráter se perderia, vindo a educação a receber, progressivamente, um cunho instrumental e prático, voltado para o crescente mercado de trabalho.

Temos aqui que a abordagem da questão da educação é, na verdade, um profundo questionamento da própria função e do propósito da prática educativa, a qual Nietzsche diagnosticou como estando, já em sua época, cada vez mais submissa e atrelada aos interesses de uma economia de mercado, mero adestramento e preparação para o mercado de trabalho, uma vez que seu discurso se constrói a partir de uma visão extremamente crítica ao surgimento do ensino profissionalizante na Alemanha do período.

Contudo, pode ser observado que as mudanças que Nietzsche critica não ocorreram só na Alemanha, mas caracterizam a história moderna da educação como um todo, e muito menos é um fenômeno restrito àquela época, posto ter prosseguido, através de diferentes reconfigurações, até resultar no atual modelo fragmentário de disciplinas, entre as quais, na maior parte das vezes, o estudante não consegue ver nexo, o que 
potencializa a relevância da crítica Nietzschiana. A cultura hoje seria o agrupamento de caprichos momentâneos, moda, opinião pública e cultura jornalística (a propalada cultura de massa "fabricada" pela Indústria Cultural, na qual os homens "estudam" para "aprender a ganhar dinheiro" e ganham dinheiro para consumir, mantendo o sistema em movimento - e, muitas vezes, consumir "bens culturais", pois até a cultura parece se tornar um grande comércio!). Do mesmo modo o ensino, que não mais visava a formação integral do homem (que seria aquela na esteira da afirmação nietzschiana da idealidade da cultura grega e que, por pretender retomar os valores "clássicos", intenciona formar homens cultos, capazes de exercitar de maneira clara e harmoniosa todas as suas potencialidades), passou a ser tão somente ensino profissionalizante. (FRAGOZO, 1974)

São essas as transformações que Nietzsche constata já em sua época, e que conduzem a importantes mudanças não só no conceito de cultura socialmente apregoado como também no modelo de educação considerado ideal, defendido e então implementado pelo Estado. Nietzsche (2003) apontara, no texto Sobre o futuro de nossos estabelecimentos de ensino, escrito pouco antes da III Intempestiva, em 1872, um quadro peculiar na Alemanha de sua época: a crença amplamente difundida na necessidade e na possibilidade de uma "cultura geral" (que para Nietzsche não detém valor genuíno, não passando de agrupamento de superficialidades, como uma “cultura jornalística") versus a realidade de miséria cultural existente, empreendida a partir da redução das escolas a "centros profissionalizantes" e das universidades a "centros especializados".

No sexto item da III Consideração Intempestiva: Schopenhauer educador (2003), Nietzsche virá a apontar como, em sua época - que ainda é a nossa, no sentido de que, como diria Heidegger (2000) a época atual é ainda a "consumação da era moderna, o acirramento de sua problemática" -,

Filosofia e Educação [RFE] - volume 8, número 3 - Campinas, SP

Outubro de 2016-Janeiro de 2017 - ISSN 1984-9605 - p. 275-294 
duas coisas se opõem à cultura autêntica: o "egoísmo dos negociantes" e o “egoísmo do Estado", que são os grandes responsáveis pela transformação da cultura em mera cultura utilitarista, um misto de bem de consumo e formação para o trabalho, que é a formação moderna do jovem, apresentando apenas dois objetivos, ligados entre si: educar para ganhar dinheiro, porque é o dinheiro - e nada mais - que trará felicidade, e formar para trabalhar, para adequar o jovem aos meios de produção, integrando-o às instituições já existentes e conformando-o à sociedade vigente.

A crítica de Nietzsche se mostra assertiva. Como podem os interesses do Estado ser configuradores da cultura? Para Nietzsche, cultura genuína e Estado caminham em lados opostos. Em sua época (e ainda na nossa...) o critério de avaliação da cultura (dos "bens culturais") se torna o critério das necessidades do consumidor, a cultura paulatinamente se torna um produto a ser consumido, a ponto de a formação de um jovem, que antes deveria ser voltada para uma cultura autêntica - isto é, entendida como cultivo de si, como formativa e integralizadora das potencialidades individuais de cada um - se tornar mera capacitação para ganhar dinheiro, arrumar um emprego, assumir seu lugar no mecanismo social, satisfazer as necessidades do rebanho.

Desse modo, a educação a serviço do Estado não é mais que um instrumento de manutenção do status quo, a formar cidadãos dóceis para o mercado. Essa é a educação propalada nos estabelecimentos de ensino de sua época, comparada por Nietzsche a um "processo de mediocrização universal". Os atuais estabelecimentos de ensino pecariam por sua "pobreza de espírito pedagógico", formam alunos em massa, não atentando para sua formação individual.

A assim chamada "cultura geral" moderna seria aquela em que se sabe um pouco de tudo e se acaba por não saber nada, ou ainda se sabe 
muito de uma parcela tão ínfima do real que se acaba por perder a noção do todo. Para Nietzsche, seria não mais que uma "barbárie cultivada", termo do qual a Escola de Frankfurt depois se apropriará.

Mas será somente tal cultivo da barbárie que se pode esperar da educação e da cultura? Em texto anterior, mas também de 1874, chamado II Consideração Intempestiva: da utilidade e desvantagem da História para a vida, Nietzsche (2003) já demonstrara como a História precisa estar sempre "a serviço da vida", sendo mais do que um "monumento" inútil ao que passou. Pois se a História traz em si a possibilidade de ser útil para a vida, também traz a possibilidade de debilitá-la em sua dinâmica originária, se a acorrenta. (CASANOVA, 2003)

O mesmo também se aplica à cultura e à educação: embora elas possam ser um entrave empobrecedor da vida (como no caso da era moderna), também podem ser um elemento potencializador da própria vida, este sim um objetivo a ser perseguido - e é essa possibilidade que constitui para Nietzsche a raiz de toda cultura e educação "autênticas". "Que a vida seja o valor máximo!” será o mote perseguido por Nietzsche em suas obras futuras. (KLOSSOWSKI, 2000)

Como buscamos alcançar, a discussão sobre a educação empreendida por Nietzsche é, na verdade, um profundo questionamento de sua própria função e propósito, a educação estando, já em sua época, cada vez mais submissa e atrelada aos interesses de uma economia de mercado, reduzida a mero adestramento e preparação para o mercado. Seu discurso se constrói, como procuramos mostrar, a partir de uma visão crítica do surgimento do ensino profissionalizante na Alemanha do período. 


\section{Educação como cultivo de si: a vida como obra de arte}

Nesse contexto, pode-se retomar a temática que Michel Haar (2000) vislumbra ao abordar o pensamento nietzschiano: o da vida como obra de arte. O homem seria para Nietzsche a obra de arte que a própria natureza determina e visa a ser alcançada - mas que a indústria, o Estado e uma "especialização" podem degenerar e limitar, em vez de conduzir à realização integral. A meta da relação mestre-discípulo é a educação autêntica, que o discípulo também venha a se tornar um mestre. A educação como cultivo de si é aquela na qual o homem vê a si mesmo como obra de arte, a ser sempre melhorada e burilada ao longo de toda a sua vida.

Contra a mediocridade da cultura jornalística, Nietzsche busca a possibilidade de uma "vida verdadeiramente artística", no sentido de uma vida plena, afirmativa da vida em sua inteireza trágica. Contra o "animal de rebanho", o da virtude ressentida, apregoada pelo cristianismo, Nietzsche levanta a bandeira do homem solitário, capaz de manter sua autonomia diante dos poderes estabelecidos. Um ponto interessante da III Intempestiva é a ponte que Nietzsche faz entre a falência dos valores cristãos e a impropriedade da cultura moderna.

A que chegou finalmente toda esta reflexão sobre as questões morais, com a qual toda sociedade nobre e evoluída esteve, porém, preocupada em todas as épocas? Não há mais modelos ilustres e não há mais reflexão desse tipo. Vive-se de fato do capital de moralidade acumulado por nossos ancestrais e da herança deles, que não sabemos mais fazer crescer, mas somente dissipar. $\mathrm{Na}$ nossa sociedade, ou não se fala absolutamente destas coisas, ou se o faz com um tal acanhamento e uma tal 
inexperiência de orientação naturalista, que não pode suscitar senão a náusea. Foi assim que nossas escolas e nossos mestres chegaram a fazer simplesmente abstração de qualquer educação moral a se contentar com um puro formalismo; e a virtude é uma palavra com a qual professores e alunos não querem mais pensar nada, uma palavra fora de moda da qual se ri - e pior ainda quando não se ri, porque então é a hipocrisia. (NIETZSCHE, 2003, p. 145)

Acredito que aí já se pode antever uma prévia de temas que depois ele abordaria na fase final de seu pensamento, como a crítica aos valores do ocidente por seu caráter "fraco" - que aparecerá em livros como Para além do Bem e do Mal (1886) e Genealogia da Moral (1887) - e, indo ainda mais longe, a crítica ao niilismo como descaminho da cultura ocidental, crítica que se torna ainda mais forte não só no seu Assim falava Zaratustra (1885) mas também no Crepúsculo dos ídolos (1888), pois esse mesmo trecho assim continua:

A explicação desta indolência e da forte estiagem de todas as forças morais é difícil e complicada. Porém, quem quer que leve em consideração a influência do cristianismo vitorioso sobre a moral do nosso velho mundo, este também não tem absolutamente o direito nem de ignorar a reação do cristianismo em vias de sucumbir, nem o seu destino cada vez mais visível na nossa época. Pela grandeza moral de seu ideal, o cristianismo ultrapassou tanto os sistemas de moral antigos e o sentimento natural que reina uniformemente 
neles, que ficou insensível a este natural e achou que ele era repugnante; [...]. O ódio hereditário do que é natural e que, por outro lado, o atrai [ao homem moderno], renovado por este mesmo natural, o desejo de achar um ponto de apoio em algum lugar, a impotência de seu conhecimento que titubeia entre o bem e o melhor, tudo isto engendra uma inquietude, uma confusão na alma moderna, que a condena a ser estéril e sem alegria. (NIETZSCHE, 2003, p. 145-146)

Vemos assim uma primeira relação entre a moral ressentida do cristianismo, sua falência, e o niilismo como única consequência possível à época contemporânea. O niilismo (como Heidegger sobretudo interpretará a obra de Nietzsche) é a consequência direta da moral cristã e de sua falência que conduziu o homem moderno a negação do valor da vida. A superação do niilismo e a afirmação da vida como valor máximo é o caminho a que conduz o pensamento nietzschiano. Neste sentido, mesmo sua posição e crítica diante da educação em sua época se inscrevem nesse escopo.

Ainda que a reflexão de Nietzsche pareça ir na contramão de muitas das discussões contemporâneas sobre a educação, hoje ainda marcadas em alguma medida por um viés pragmático e utilitário, temos que convir que sua reflexão não se exime de pensar as mudanças pelas quais passou (e passa) a educação, até suas últimas consequências, se inserindo no bojo de uma crítica ainda mais dura ao que Nietzsche entende como a raiz da decadência da cultura ocidental.

Se, como coloca Benedito Nunes (2000), a época contemporânea é a personificação da apatridade do homem, de sua ausência de cultura autêntica - esfarelada em prol da economia de mercado e sua cultura 
jornalística, como não pensar a atualidade de tal questionamento? A assim chamada "cultura da informação", que é a nossa (e informação não é conhecimento, muito menos sabedoria...), é hoje em todo lugar disseminada e exaltada como sendo a verdadeira cultura. Neste sentido, ao considerar a questão da educação através do modelo de Schopenhauer como educador, Nietzsche se mostra mais do que nunca preocupado com o destino da humanidade.

\section{Algumas observações finais}

É em Humano Demasiado Humano, obra de 1878, que o afastamento de Nietzsche em relação a Schopenhauer se torna definitivo. É nesse contexto também que a arte ganha força como a arte de criar a si mesmo, de desenvolver as próprias potencialidades - a arte da educação. Nos termos que Jorge Larrosa (2002, p.45) coloca:

Chega a ser o que és! Talvez a arte da educação não seja outrora senão a arte de fazer com que cada um torne-se em si mesmo, até sua própria altura, até o melhor de suas possibilidades. Algo, naturalmente, que não se pode fazer de modo técnico nem de modo massificado

A vida como obra de arte indica, então, a possibilidade de o homem se apropriar de sua própria existência.

Assim, para Nietzsche, esse tornar-se o que se é não é uma volta ao eu verdadeiro, nem o desmascaramento dos obstáculos fictícios que entravam a cultura do eu. O "eu" é uma criação, uma construção, um cultivo de si 
permanente. Para ousar ser um si mesmo é preciso antes de tudo de uma tarefa: dar estilo ao próprio caráter, acomodando os vários aspectos de sua própria natureza, inclusive as fraquezas, colocando-as em uma totalidade aprazível de acordo com um plano artístico. (DIAS, 2008, p.49)

A relação entre vida e arte no processo de criação de si não é, contudo, tarefa apenas individual, antes se inscreve na tensão entre individual e coletivo, o singular e o padronizado. Como pensar a construção de si sem girar em torno dessas oposições, mencionadas no início deste texto, como características da modernidade? O ser humano que se pensa a si mesmo como obra de arte, necessariamente, realiza seus esforços tanto para sua existência em sociedade quanto para sua própria condição de sujeito singular. As críticas de Nietzsche aos estabelecimentos de ensino profissionalizante na Alemanha de sua época mostram-se ainda relevantes, porquanto tratam da educação na modernidade - lidando com características que emergem em todo o mundo ocidental, de um jeito ou de outro. A maior exigência feita hoje a um indivíduo é não apenas a construção de si mesmo, mas sua inserção no mercado de trabalho como forma de contribuição útil para a sociedade. Diante da emergência disso que Nietzsche denominaria como uma pseudocultura (por seu caráter geral e jornalístico) e do desenvolvimento de um saber fragmentário e cada vez mais especializado, a educação e seu propósito (como autoformação ou cultivo de si) ainda são capazes de resistir? A crítica realizada por Nietzsche é "antes de tudo, e no final de contas, uma crítica ao mundo contemporâneo" (LÖWITH, 1969, p. 367) e ao elemento humano que nele consegue - ou como consegue - se inserir e se construir. 


\section{Referências bibliográficas}

CASANOVA, M. A. O Instante Extraordinário: vida, história e valor na obra de

Friedrich Nietzsche. Rio de Janeiro: Forense Universitária, 2003.

DIAS, R. Nietzsche e Foucault: a vida como obra de arte. In: PIMENTA, O.;

KANGUSSU, I. (orgs). O cômico e o trágico. Rio de Janeiro: 7 Letras, 2008.

FRAGOSO, M. X. Nietzsche e a educação. In: Revista Trans/Form/Ação. Marília, v. 1, p. 277-293, 1974.

HAAR, M. A obra de arte: ensaio sobre a ontologia das obras. Trad. Maria Helena Kühner. Rio de Janeiro: DIFEL, 2000.

HEIDEGGER, M. Nietæssche: Metafísica e Niilismo. Trad. Marco Antônio Casanova. Rio de Janeiro: Relume Dumará, 2000.

KLOSSOWSKI, P. Nietəsche e o Círculo Vicioso. Trad. Hortência S. Lencastre. Rio de Janeiro: Pazulin, 2000.

LARROSA, J. Nietzssche \& a Educação. Trad. Alfredo Veiga-Neto. Belo Horizonte: Autêntica, 2002.

LÖWITH, K. De Hegel à Nieţssche. Paris: Editions Gallimard, 1969.

MACHADO, R. Zaratustra, tragédia nietžscheana. Rio de Janeiro: Jorge Zahar Editor, 1999.

MARTON, S. Nietşsche: a transvaloração dos valores. São Paulo: Moderna, 1993.

MELO SOBRINHO, N. C. A Pedagogia de Nietzsche. In: NIETZSCHE, F. Escritos sobre Educação. Trad. Noéli Correia de Melo Sobrinho. São Paulo: Edições Loyola, 2003.

NIETZSCHE, F. A filosofia na idade trágica dos gregos (1873). Trad. Maria Inês M. de Andrade. Rio de Janeiro: Elfos, 1995. Assim falava Zaratustra (1885). Tradução de Mário da Silva. Rio de Janeiro: Civilização Brasileira, 1981. 
- Genealogia da moral (1887). Trad. Paulo César de Souza. São Paulo: Companhia das Letras, 1998.

- Humano, demasiado bumano (1878). Trad. Paulo César de Souza. São

Paulo: Companhia das Letras, 2000.

. II Consideração Intempestiva: da utilidade e desvantagem da História para a vida. (1874). Trad. Marco Antônio Casanova. Rio de Janeiro: Relume Dumará, 2003.

III Consideração Intempestiva: Schopenhauer Educador (1874). In: Escritos sobre Educação. Trad. de Noéli Correia de Melo Sobrinho. São

Paulo: Edições Loyola, 2003.

- Nascimento da Tragédia, on Helenismo e Pessimismo (1872). Trad. J.

Guinsburg. São Paulo: Companhia das Letras, 1998.

- O Crepúsculo dos Ídolos ou como Filosofar com o Martelo (1888). Trad. Paulo

César de Souza. São Paulo: Companhia das Letras, 2006.

- Para além do Bem e do mal (1886). Trad. Paulo César de Souza. São Paulo:

Companhia das Letras, 2005.

. Sobre o Futuro de nossos Estabelecimentos de Ensino (1872). In: - Escritos sobre Educação. Trad. Noéli Correia de Melo Sobrinho. São

Paulo: Edições Loyola, 2003.

: Werke in zwwei Band. München: Carl Hanser Verlag, 1954 (I) e 1955 (II).

NUNES, B. O Nieţssche de Heidegger. São Paulo: Ágora, 2000.

SUAREZ, R. Nota sobre o conceito de Bildung (formação cultural). In: Revista Kriterion, vol.46, n.112, pp.191-198, 2005.

WEBER, J. F. Singularidade e formação (Bildung) em Schopenhauer como educador de Nietzsche. In: Revista Educação e Pesquisa, vol.35, n.2, p.251-264, 2009. 